\title{
The Long-term Projection of Surface Runoff in the Regions above Danjiangkou in Hanjiang River Basin based on Water-energy Balance
}

\author{
Jun Yin ${ }^{1}$, Zhe Yuan ${ }^{2 *}$, Run Wang ${ }^{1}$ \\ ${ }^{1}$ Faculty of Resources and Environmental Science, Hubei University, Wuhan 430062, China; \\ ${ }^{2}$ Changjiang River Scientific Research Institute, Changjiang Water Resources Commission of the Ministry of Water Resources of China, \\ Wuhan 430010, China;
}

\begin{abstract}
The projection of surface runoff in the context of climate change is important to the rational utilization and distribution of water resources. This study did a case study in regions above Danjiangkou in Hanjiang River Basin. A basin scale hydrological model was built based on macroscale processes of surface runoff and water-energy balance. This model can describe the quantity relationship among climatic factors, underlying surface and surface runoff. Driven by hypothetical climatic scenarios and climate change dataset coming from CMIP5, the climate change impacts on surface runoff in the regions above Danjiangkou in Hanjiang River Basin can be addressed. The results showed that: (1) Compared with other distributed hydrological models, the hydrological model in this study has fewer parameters and simpler calculation methods. The model was good at simulating annual surface runoff. (2) The surface runoff was less sensitivity to climate change in the regions above Danjiangkou in Hanjiang River Basin. A $1{ }^{\circ} \mathrm{C}$ increase in temperature might results in a surface runoff decrease of $2 \sim 5 \%$ and a $10 \%$ precipitation increase might result in a streamflow increase of $14 \sim 17 \%$. (3) The temperature across the Fu River Basin were projected to increase by $1.4 \sim 2.3^{\circ} \mathrm{C}$ in 1961 to 1990 compared with that in 1961 to 1990 . But the uncertainty existed among the projection results of precipitation. The surface runoff was excepted to decrease by $1.3 \sim 23.9 \%$ without considering the climate change projected by NorESM1-M and MIROC-ESM-CHEM, which was much different from other GCMs.
\end{abstract}

\section{Introduction}

According to IPCC AR5, since the last century, most places in the world has been suffering climate change whose main characteristic is global warming. Mean temperature of the global sea and land surface has increased by $0.85^{\circ} \mathrm{C}$ from 1880 till 2012 . What's more, the surface temperature amplification during the recent 30 years is higher than any period since $1850^{[1]}$. Increase of temperature will accelerate the general atmospheric circulation and hydrologic cycle, thus resulting the reallocate of global water resource in different scale and affecting the global ecological environment and economic development of society ${ }^{[2-3]}$. So the projection of the surface runoff variation in the context of climate change will provide scientific proof for the planning management, development and utilization and ecological environment protection of water resources ${ }^{[4]}$, and it has become a hot spot and frontier issue ${ }^{[5-7]}$.

Mostly, the projection of surface runoff variation in the context of climate change will follow a pattern which is "design of future scenario-hydrological model-impact assessment" ${ }^{\text {"[-11] }}$. Hydrological model is the key tool to project the future surface runoff. Three challenges exist in methods based on the refined hydrological simulation to project surface run off variation in big scale. On the theoretical level, since the dominant factor of water cycle will differ as the time scale differs. Parameter calibration and model test will be done in relatively small time scales, such as monthly and daily scale. When the results are applied on the surface runoff analysis in yearly or multiyear scale, whether the model and parameters can reflect the dominant process and parameter characteristics in a large time scale still remains to be discussed ${ }^{[12-14]}$. On the technological level, due to the significant difference of climatic and under surface characteristics of different basins in China, it is of great difficulty to establish one hydrological model which is universal in China and in the meantime could reflect regional characteristics ${ }^{[15]}$. On the application level, refined hydrological model has a high requirement for data and calculation. Detailed climatic information, under surface data, water intake and use data and project scheduling data are all needed ${ }^{[16]}$. This kind of refined hydrological model can be used in typical basin and region, but is hard to be widely promoted in large region.

This research chose the regions above Danjiangkou in 
Hanjiang River Basin as the study area. With the macroscopic mechanism of surface runoff formation as the starting point, basin scale hydrological model which could describe quantitative relation between climatic factors, under surface factors and surface runoff in large scale was established. The sensitivity of the study area to climate change was assessed. With the aid of the output of CMIP5, future surface runoff in the study area has been projected, so as to provide reliable scientific proof for the planning design, development and utilization and operation management of water resources system in the regions above Danjiangkou in Hanjiang River Basin.

\section{Study area}

Hanjiang River is the largest tributary of the left bank of middle reaches in Yangtze River. Hanjiang River originates from the south of Qinling Mountains and flows through Shaanxi Province and Hubei Province with its length of $1577 \mathrm{~km}$. Dragon King Temple in Hankou Wuhan City is the place where Hanjiang River affluxes into the Yangtze River. Hanjiang River Basin is located between $30^{\circ} 4^{\prime} \sim 34^{\circ} 12^{\prime} \mathrm{N}$ and $106^{\circ} 5^{\prime} \sim 114^{\circ} 17^{\prime} \mathrm{E}$ whose total area is $159000 \mathrm{~km}^{2[17]}$. Hanjiang River Basin shows an character of "higher northwest part and lower southeast part" on the whole. Regions above Danjiangkou has big relief amplitude whose south part is the Jingshan mountain area of Daba Mountain and north part is the Huaiyang mountain area of Qinling. Regions below Danjiangkou has relatively small relief amplitude and it is the river valley and flooded plain ${ }^{[18]}$.

There are five fourth and above fourth level rivers in Hanjiang River Basin, which are Hanjiang, jushui River, Duhe River, Danjiang River and Tangbaihe River. Hanjiang River Basin is divided into upper, middle and lower reaches with Danjiangkou and Zhongxiang. The average gradient of reaches above Danjiangkou of Hanjiang River Basin is larger than 0.6\%o. The river length is $925 \mathrm{~km}$ and is about $59 \%$ of the whole length of the main stream. The area of the regions above Danjiangkou of Hanjiang River Basin is $95200 \mathrm{~km}^{2}$ and is $60 \%$ of the total basin $^{[19-20]}$.

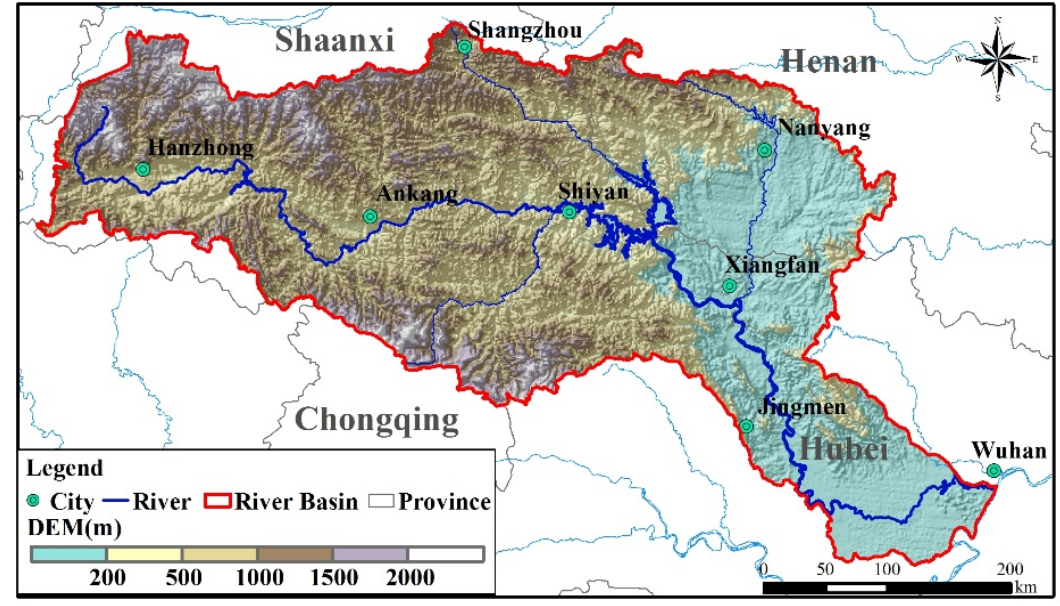

Fig.1 Location of regions above Danjiangkou in Hanjiang River Basin

\section{Data and method}

\subsection{Data}

Observed meteorological data used in this research is the daily ground climatological data set of China (V3.0) provided by National Meteorological Information Center (NMIC) of the China Meteorological Administration (CMA). This data set covers meteorological data (atmospheric pressure, temperature, relative humidity, precipitation, evaporation, wind direction, wind speed, et al.) from 824 national ground stations. This research used data from 21 meteorological stations located in and around the study area ranging from 1956 2013. Daily inflow of Danjiangkou reservoir from 1956 2008 was used as runoff data, which was further processed to get the surface runoff depth in the regions above Danjiangkou of Hanjiang River Basin.

Interpolated and corrected output of five climate models provided by ISI-MIP (The Inter-Sectoral Impact Model Intercomparison Project) was used in this research. Interpolation and correction were carried out by bilinear interpolation and statistical bias correction based on probability distribution ${ }^{[21-23]}$. The selected five climate models in ISI-MIP are GFDL-ESM2M, HADGEM2-ES, IPSL-CM5A-LR, MIROC-ESM-CHEM and NORESM1M. Output of these five climate models includes temperature and precipitation with a resolution of $0.5^{\circ} \times 0.5^{\circ}$. These five climate models include four scenarios: RCP2.6, RCP4.5, RCP6.0 and RCP8.5. Time ranges of simulation is from Jan $1^{\text {st }}, 1960$ to Dec $1^{\text {st }}, 2099$. In this research, we used three scenarios, which are RCP2.6, RCP4.5 and RCP8.5, to stand for low, middle and high scenario. Study phase is 1960 2050. Surface runoff depth in 2020 2050 was projected.

\subsection{Hydrological-thermal balance model in basin scale}

For a certain closed basin, its hydrological and climatic characteristics fit into the water balance equation and energy balance equation. During the hydrology research, water balance and energy balance are often used to establish water balance model to simulate the water cycle in a basin. 
Based on water balance and energy balance, correlational relationship between precipitation, evaporation, land use and runoff can be built. Thus, the hydrological-thermal balance model in basin scale can be established.

$$
\begin{gathered}
R=P-E+\Delta W \\
R_{n}=\lambda E+H+G \\
E=f\left(E_{0}, P\right)
\end{gathered}
$$

where, $P$ is precipitation; $E$ is actual evaporation; $\Delta W$ is variation of soil moisture content which is close to 0 in long time scale; $R_{n}$ is the net radiation flux reaching the ground; $G$ is the soil thermal flux; $\lambda E$ is latent heat flux of vaporization; $H$ is the sensible heat flux; $E_{0}$ is evaporative capacity; $\omega$ is soil parameters related to land use type. $E_{0}$ can be calculated by Penman-Monteith method recommended by Food and Agriculture Organization (FAO).

$E$ is actual evapotranspiration, which can be calculated by Budyko curve. The Budyko assumption considers that a coupled equilibrium relation (hydrological-thermal balance relation) exists between the water and energy in a basin. An empirical relation curve was also given to describe the quantitative relation between multi-year average precipitation, latent evapotranspiration and actual evapotranspiration. The most widely used Budyko curves are listed in Table 1.

Table 1 The Expressions of Budyko curve

\begin{tabular}{cc}
\hline Equation & Reference \\
$E / P=1-\exp ^{-\phi}$ & Schreiber (1904) ${ }^{[24]}$ \\
$E / P=\phi \tanh (1 / \phi)$ & Ol'dekop (1911) ${ }^{[25]}$ \\
$E / P=\left[1+(1 / \phi)^{2}\right]^{-0.5}$ & Turc (1953) ${ }^{[26]}$ \\
$E / P=\left[\phi \tanh (1 / \phi)\left(1-\exp ^{-\phi}\right)\right]^{0.5}$ & Pike (1964) ${ }^{[27]}$ \\
$E / P=1+\phi-\left(1+\phi^{\omega}\right)^{1 / \omega}$ & Budyko (1974) ${ }^{[28]}$ \\
$E / P=1-\left(\phi \cdot \gamma^{\frac{\gamma}{\phi}} \exp ^{-\gamma}\right)\left[\Gamma\left(\frac{\gamma}{\phi}\right)-\Gamma\left(\frac{\gamma}{\phi}, \gamma\right)\right]^{-1}$ & Baopu Fu (1981), Zhang et al. (2004) ${ }^{[29-30]}$ \\
\end{tabular}

During many Budyko curves, the Baopu Fu equation is a analytic expression with mathematical physical meaning ${ }^{[32]}$. This equation describes the relationship between precipitation, evaporative capability and actual evaporation as follows:

$$
\frac{E}{E_{0}}=1+\frac{P}{E_{0}}-\left[1+\left(\frac{P}{E_{0}}\right)^{\omega}\right]^{1 / \omega}
$$

where, $E$ is actual evaporation; $E_{0}$ is evaporative capacity; $P$ is annual precipitation; $\omega$ is empirical parameter which is related to land use type.

Based on equation (4) and (1), hydrological-thermal balance model in basin scale based on Baopu Fu can be obtained. Then runoff simulation and projection can be $\operatorname{made}^{[33]}$.

$$
R=E_{0}\left\{\left[1+\left(\frac{P}{E_{0}}\right)^{\omega}\right]^{1 / \omega}-1\right\}
$$

where, $\omega$ can be calibrated by runoff $(R)$, precipitation $(P)$ and evaporative capability $\left(E_{0}\right)$ over a given period.

Determination coefficient $\left(R^{2}\right)$, Nash-Sutcliffe efficiency coefficient (NSE) and relative error $(R E)$ were selected to assess the performance of model. Equations are listed as follows:

$$
\begin{aligned}
& R^{2}=\frac{\left[\sum_{t=1}^{N}\left(q_{o b s}(t)-\overline{q_{o b s}}\right)\left(q_{\text {sim }}(t)-\overline{q_{\text {sim }}}\right)\right]^{2}}{\sum_{t=1}^{N}\left(q_{o b s}(t)-\overline{q_{o b s}}\right)^{2} \sum_{t=1}^{N}\left(q_{\text {sim }}(t)-\overline{q_{s i m}}\right)^{2}} \\
& N S E=1-\frac{\sum_{t=1}^{N}\left[q_{o b s}(t)-q_{\text {sim }}(t)\right]^{2}}{\sum_{t=1}^{N}\left[q_{o b s}(t)-\overline{q_{o b s}}\right]^{2}} \\
& R E=\frac{\frac{q_{\text {sim }}-\overline{q_{o b s}}}{\overline{q_{o b s}}} \times 100 \%}{}
\end{aligned}
$$

where, $q_{\text {obs }}(t)$ and $q_{\text {sim }}(t)$ are the observed and simulated monthly runoff respectively; $\overline{q_{o b s}}$ and $\overline{q_{\text {sim }}}$ are the average value of observed and simulated monthly runoff respectively. In general, higher $R^{2}$, bigger NSE and smaller $|R E|$ means better performance. When $R^{2}>0.6$, 
$N S E>0.5$ and $|R E|<15 \%$, the model can be applied in the study area ${ }^{[34-36]}$.

\subsection{Analysis on the impact of climate change on runoff}

This research analyzed the impact of climate change on runoff from two respects: (1) presumed climate change scenarios were established to analyze the sensitivity of runoff to climate change; (2) output of future climate change were utilized to drive the hydrological-thermal balance model, so as to project the impact of future climate change on runoff. Specific process is as follows:

The precipitation and temperature were presumed to change by a certain degree $(\Delta P$ and $\Delta T)$. Combined with the established hydrological-thermal balance model, equation (9) can be used to quantify the sensitivity of runoff to climate change.

$$
\delta(\Delta P, \Delta T)=\frac{f(P+\Delta P, T+\Delta T)-f(P, T)}{f(P, T)} \times 100 \%
$$

Where, $P$ and $T$ stand for precipitation and temperature respectively; $\Delta P$ and $\Delta T$ stand for the variation amplitude of precipitation and temperature respectively and they are the response function between runoff and precipitation and temperature; $\delta(\Delta P, \Delta T)$ stands for the sensitivity of runoff to climate change. This research took1961-1990 as the baseline. Based on this, the precipitation was presumed to change by $+30 \%,+20 \%,+10 \%, 0 \%,-10 \%$ and $-20 \%$ respectively and the temperature was presumed to change by $+3^{\circ} \mathrm{C},+2^{\circ} \mathrm{C},+1{ }^{\circ} \mathrm{C}, 0^{\circ} \mathrm{C},-1^{\circ} \mathrm{C},-2^{\circ} \mathrm{C}$ and $3^{\circ} \mathrm{C}^{[37-38]}$ 。

In order to eliminate the impact of systematic deviation of climate model simulation, precipitation and temperature simulated by climate models were used to drive the hydrological-thermal balance model. Relative change of simulated runoff was used to stand for the future variation. The base line is also 1961 1990 and the future projected period is $2020 \sim 2050$.

\section{Results}

\subsection{Assessment of hydrological-thermal balance model simulation in basin scale}

This research took runoff depth in the regions above Danjiangkou in Hanjiang River Basin during 1956 2013 to do calibration and verification. The calibration period is 1956 2000 and the verification period is 2001 2013. The calibrated parameter $\omega$ is 1.804 . NSE, $R^{2}$ and $R E$ during the calibration period are $0.90,0.93$ and $-0.97 \%$ respectively; and those during the verification period are $0.89,0.94$ and $5.02 \%$ respectively (Fig. 2 and Table 2). Simulated results show that it is feasible to use basin scale hydrological-thermal balance model to simulate the runoff depth in regions above Danjiangkou of Hanjiang River Basin and it can be utilized to project the runoff depth in the study area.

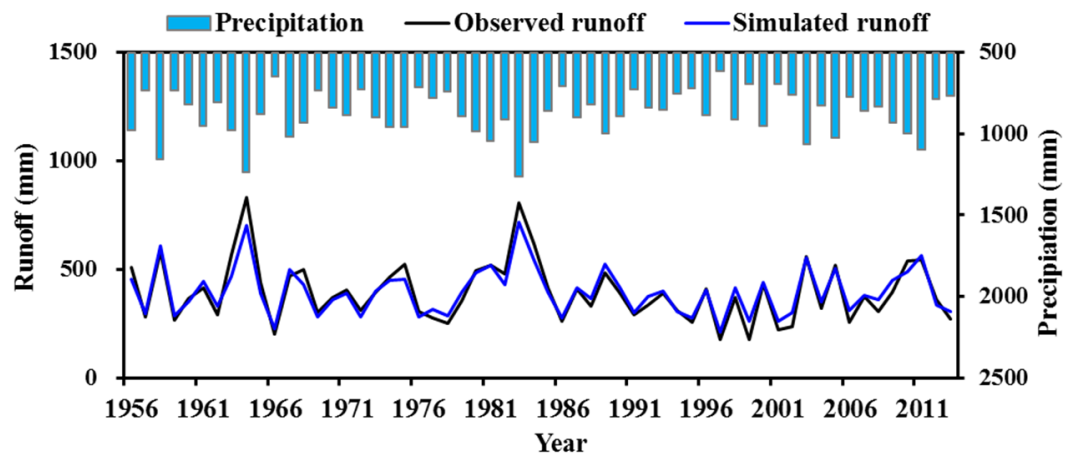

Fig.2 The observation and simulation of runoff depth in in the regions above Danjiangkou of Hanjiang River Basin

Table 2 Performance of the hydrological model based on water-energy balance

\begin{tabular}{cccc}
\hline Period & $N S E$ & $R^{2}$ & $R E(\%)$ \\
\hline Calibration Period (1956 2000) & 0.90 & 0.93 & -0.97 \\
Verification Period (2001 2013) & 0.89 & 0.94 & 5.024 \\
\hline
\end{tabular}

\subsection{Sensitivity of surface runoff depth variation to climatic factors in the study area}

Monthly mean temperature $(\mathrm{Tm})$ and monthly potential evapotranspiration $\left(E T_{0}\right)$ during 1961-2010 in the study area were used to establish the statistical relationship between $T m$ and $E T_{0}$. It can be seen that temperature and potential evapotranspiration approximately fit exponential relation (Fig. 3). Based on the presumed climate change scenario and statistical relationship between temperature and evapotranspiration, potential evapotranspiration in different scenarios can be calculated. Furthermore, combined with the established hydrological-thermal balance model of the study area, surface runoff depth in different climate scenarios can be simulated. According to equation (9), the impact of precipitation change and temperature change on surface runoff depth can be calculated (Fig. 4): (1) when the precipitation is constant, surface runoff depth will decrease by 2 to $5 \%$ ( 9 to $20 \mathrm{~mm}$ ) as temperature increases by each degree centigrade; when the temperature is constant, surface runoff depth will 
increase by 14 to $17 \%$ (60 to $70 \mathrm{~mm}$ ) as precipitation increases by each $10 \%$.

Research by Chiew (2006) showed that bigger runoff coefficient in a basin means less sensitivity to climate change in general. The multi-year mean precipitation and surface runoff depth of the study area are $875.5 \mathrm{~mm}$ and $396.4 \mathrm{~mm}$ respectively and the runoff coefficient is 0.45 . According to the research carried out by Chiew, regions above Danjiangkou in Hanjiang River Basin is not sensitive to climate change. In this research, results based on hydrological-thermal balance model are consistent with that.

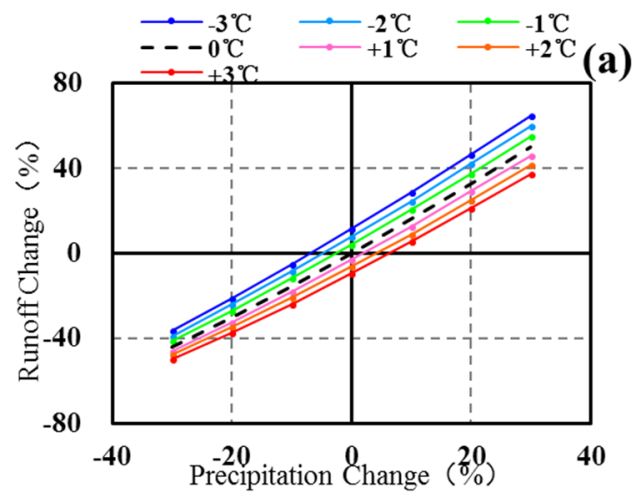

Fig.4 The relationship between runoff depth and precipitation/temperature

\subsection{Projection of surface runoff depth in regions above Danjiangkou in Hanjiang River Basin in the context of climate change}

Fig. 5 and Fig. 6 show the annual temperature and annual precipitation variation in regions above Danjiangkou in Hanjiang River Basin during 1961-2050. Future temperature has consistent changing trend. Under RCP2.6, RCP4.5 and RCP8.5, multi-year mean temperature during the changing period (2020-2050) increased by $1.4 \sim 2.1^{\circ} \mathrm{C}$, $1.4 \sim 2.0^{\circ} \mathrm{C}$ and $1.9 \sim 2.3^{\circ} \mathrm{C}$ respectively compared to that during the baseline (1961-1990) (Fig. 8(a)). The variation of future precipitation has a certain degree of uncertainty: multi-year mean precipitation in the changing period will change by $7.9 \sim 3.7 \%$ ( RCP2.6), -9.7 5.9\%( RCP4.5) and $12.7 \sim 0.5 \%$ ( RCP8.5) compared to the baseline. Under RCP2.6 and RCP8.5 scenario, projected precipitation by HadGEM2-ES and NorESM1-M will increase by $3.7 \%$ (RCP2.6, HadGEM2-ES), 0.5\% (RCP8.5, HadGEM2-ES) and 3.4\% (RCP2.6, NorESM1-M), 0.3\% (RCP8.5, NorESM1-M); while the precipitation projected by other

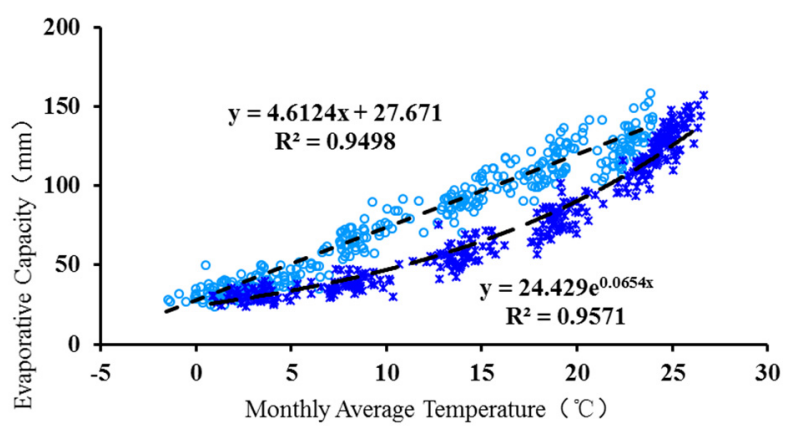

Fig.3 Relationship between temperature and potential evapotranspiration

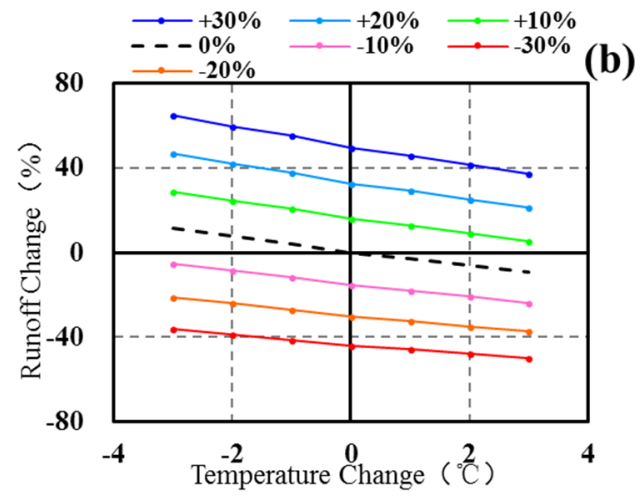

models shows a decreasing trend. Under the RCP 4.5 scenario, precipitation projected by MIROC-ESM-CHEM and NorESM1-M will increase by $5.9 \%$ and $4.5 \%$ respectively; while other models projected decreasing precipitation (Fig. 7 (b)).

Fig. 7 shows the inter-annual variation of surface runoff depth in regions above Danjiangkou in Hanjiang River Basin during 1961-2050. Among the selected $3 \times 5=15$ scenarios, future surface runoff depth under 12 scenarios will decrease, thus having apparent consistency. Climate models which projected increasing surface runoff depth are NorESM1-M under RCP 2.6 scenario $(+0.8 \%)$ and NorESM1-M and MIROC-ESM-CHEM under RCP4.5 ( $+1.9 \%$ and $+3.9 \%)$. Under other scenarios, surface runoff depth all shows a decreasing trend (-1.3 $23.9 \%$ ). The projection of surface runoff depth differs in different climate models and different scenarios: the projection of GFDL-ESM2M and IPSL-CM5A-LR decreases significantly $(-15.0 \sim-23.9 \%$ and $-15.0 \sim-17.4 \%$ respectively). The average of multi-climate models shows that future surface runoff depth will decrease by $8.3 \%, 7.1 \%$ and $12.4 \%$ under RCP2.6, RCP4.5 and RCP8.5 respectively.
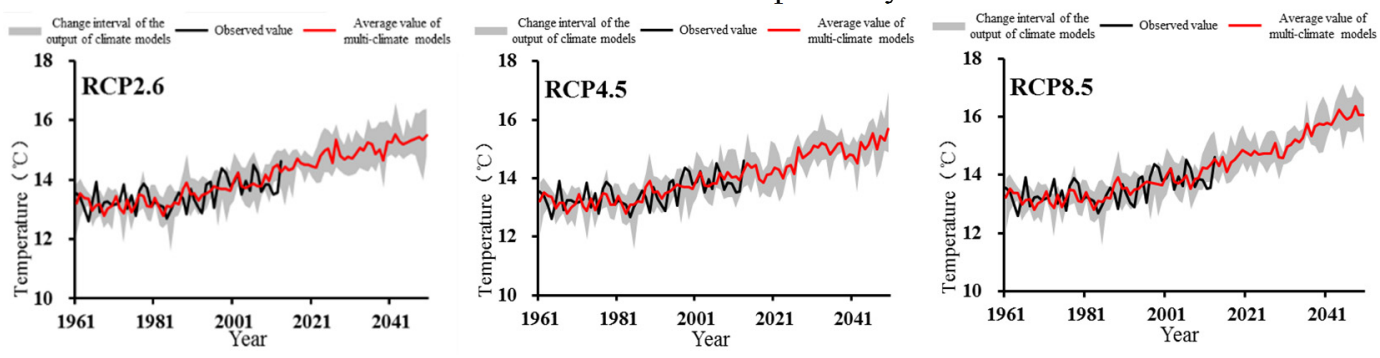

Fig.5 The temperature of regions above Danjiangkou in Hanjiang River Basin from 1961 to 2050 

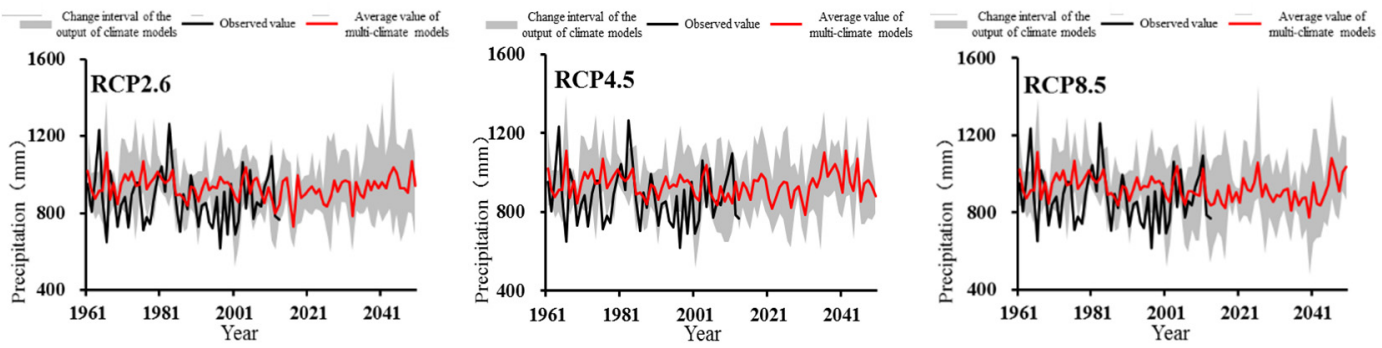

Fig.6 The precipitation of regions above Danjiangkou in Hanjiang River Basin from 1961 to 2050
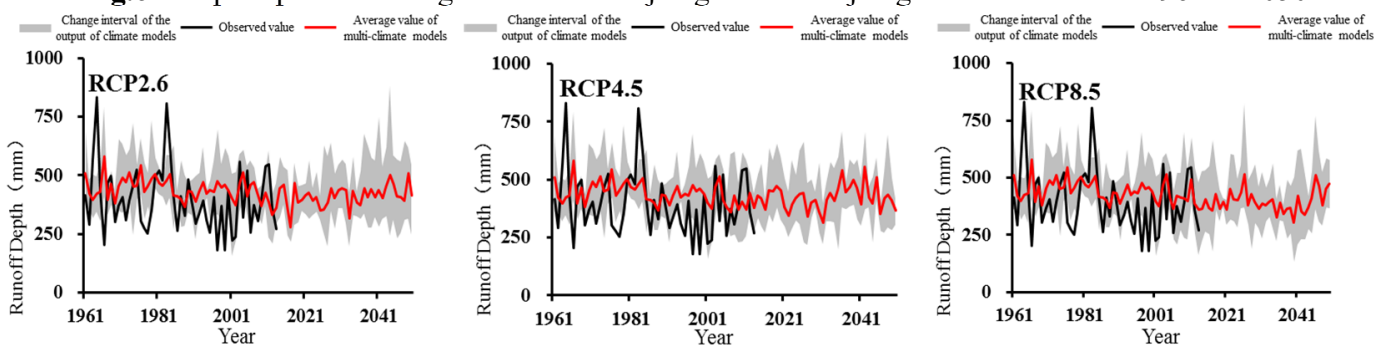

Fig.7 The runoff depth of regions above Danjiangkou in Hanjiang River Basin from 1961 to 2050
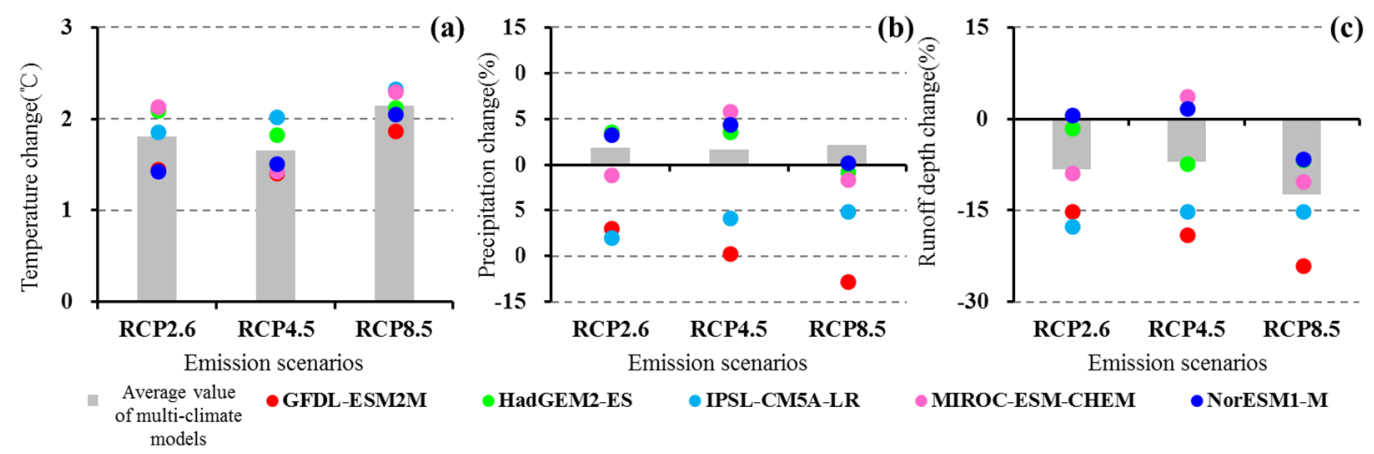

Fig.8 The change of temperature (a), precipitation (b) and runoff depth (c) compared to the baseline

\section{Conclusions}

In this research, hydrological-thermal balance model in regions above Danjiangkou in Hanjiang River Basin was established. Based on five climate models, future surface runoff depth under RCP2.6, RCP4.5 and RCP8.5 in the study area has been projected. The results are as follows:

(1) The established hydrological-thermal balance model in the study area performed well in the simulation of yearly runoff. During calibration period and verification period, $R^{2}$ and NSE are both above 0.89 , and $R E$ is less than $5.02 \%$. Thus this model can be used in the projection of future surface runoff in the study area. Compared with other distributed hydrological models, hydrological-thermal balance model established in this study has less parameters and simpler calculation.

(2) The response amplitude of surface runoff depth to climate change is related with the dry and wet background of a basin. The runoff coefficient of the study area is 0.45 and the study area is relatively humid. The study area is not sensitive to climate change: when the precipitation is constant, surface runoff depth will decrease by 2 to $5 \%$ ( 9 to $20 \mathrm{~mm}$ ) as temperature increases by each degree centigrade; when the temperature is constant, surface runoff depth will increase by 14 to $17 \%$ (60 to $70 \mathrm{~mm}$ ) as precipitation increases by each $10 \%$.

(3) Results show that the temperature in the study area has consistent increasing trend: multi-year mean temperature during the changing period (2020-2050) increased by $1.4 \sim 2.1^{\circ} \mathrm{C}, \quad 1.4 \sim 2.0^{\circ} \mathrm{C}$ and $1.9 \sim 2.3^{\circ} \mathrm{C}$ respectively compared to that during the baseline (19611990). The variation of future precipitation has a certain degree of uncertainty: multi-year mean precipitation in the changing period will change by 7.9 3.7\%( RCP2.6), 9.7 5.9\%( RCP4.5) and -12.7 0.5\%( RCP8.5) compared to the baseline. As to the interannual variation of surface runoff depth, among the selected $3 \times 5=15$ scenarios, future surface runoff depth under 12 scenarios will decrease. The main reason is that during the projection period, the variation of precipitation is relatively small which has small impact of runoff; while the increase of temperature is relatively big which will have big impact of runoff.

There are many climate models to project future climate. Due to the limitation of data and record, this research only chose five climate models. The projection of future surface runoff depth was based on the output of climate models. As a result, the rationality and correctness of the results are directedly impacted by the accuracy and rationality of the selected models. Using different climate models may get different results.

\section{Acknowledgment}

This research is supported by the CRSRI Open Research Program (Program SN:CKWV2018493/KY); National Natural Science Foundation of China (grant number:51709008); the Open Research Fund of State Key Laboratory of Simulation and Regulation of Water Cycle 
in River Basin(China Institute of Water Resources and Hydropower Research)(grant number: IWHR-SKLKF201804.

\section{Reference}

1. IPCC. Working Group I Contribution to the IPCC Fifth Assessment Report, Climate Change 2013: The Physical Science Basis: Summary for Policymakers.

2. Zhang Jianyun. Impacts of Climate Change on Water Resources in China and Its relevant scientific problems to be further studied[J]. CHINA WATER RESOURCES, 2008(2):14-18.

3. ZHANG Liping, CHEN Xiaofeng, ZHAO Zhipeng, HU Zhifang. Progress in Study of Climate Change Impacts on Hydrology and Water Resources[J]. PROGRESS IN GEOGRAPHY, 2010, 27(3): 60-67.

4. Narsimlu B, Gosain A K, Chahar B R. Assessment of future climate change impacts on water resources of upper sind river basin, India using SWAT model[J]. Water resources management, 2013, 27(10): 36473662 .

5. Liquete C, Arnau P, Canals M, et al. Mediterranean river systems of Andalusia, southern Spain, and associated deltas: a source to sink approach $[\mathrm{J}]$. Marine Geology, 2005, 222: 471-495.

6. Barnett T P, Pierce D W, Hidalgo H G, et al. Humaninduced changes in the hydrology of the western United States[J]. Science, 2008, 319(5866): 10801083.

7. CHEN Yaning, LI Zhi, FAN Yuting, WANG Huaijun, FANG Gonghuan. Research progress on the impact of climate change on water resources in the arid region of Northwest China[J]. ACTA GEOGRAPHICA SINICA, 2014, 69(9): 1295-1304.

8. Arnell N W. Climate change and global water resources[J]. Global environmental change, 1999, 9: 31-49.

9. Singh V P, Woolhiser D A. Mathematical modeling of watershed hydrology[J]. Journal of hydrologic engineering, 2002, 7(4): 270-292.

10. Praskievicz S, Chang H. A review of hydrological modelling of basin-scale climate change and urban development impacts[J]. Progress in Physical Geography, 2009, 33(5): 650-671.

11. Thompson J R, Green A J, Kingston D G, et al. Assessment of uncertainty in river flow projections for the Mekong River using multiple GCMs and hydrological models[J]. Journal of hydrology, 2013, 486: 1-30.

12. Beven K, Binley A. The future of distributed models: model calibration and uncertainty prediction[J]. Hydrological processes, 1992, 6(3): 279-298.

13. XIA Jun. Issue of Hydrological Scale[J]. Journal of Hydraulic Engineering, 1993(5):32-37.

14. Sivapalan M, Takeuchi K, Franks S W, et al. IAHS Decade on Predictions in Ungauged Basins (PUB), 2003-2012: Shaping an exciting future for the hydrological sciences[J]. Hydrological sciences journal, 2003, 48(6): 857-880.

15. QIAO Juan, ZHANG Qiang, ZHANG Jie. Preliminary Summary on Parameterization of Heterogeneous Land Surface Process and Remote Sensing Technology Research[J]. Arid Meteorology, 2008, 26(1): 73-77.

16. XU Zong-xue, CHENG Lei. Progress on studies and applications of the Distributed Hydrological Models [J]. Journal of Hydraulic Engineering, 2010, 1(3): 56.

17. GUO Sheng-lian, ZHANG Jun, GUO Jing. Flood forecasting system of Hanjiang Basin based on meteorological model[J]. Advances in Science and Technology of Water Resources, 2009, 29(3): 1-5.

18. LI Xiaoyan, REN Zhiyuan, ZHANG Chong. The correlation analysis and space-time changes of NDVI and hydro-thermal index in Hanjiang basin [J].2013,32(9): 1623-1633.

19. XU Xinwei, WU Zhonghua, YU Dan, LIU Chunhua, LI Zhongqiang, XIAO Keyan. Diversity of Aquatic Plants in Hanjiang River Basin and Possible Effects of the Engineering of Transfering Water from South China to North China on it [J]. ACTA ECOLOGICA SINICA, 2002, 22(11): 1933-1938.

20. ZHENG Shuwei, PANG Jiangli, HUANG Chunchang, ZHA Xiaochun, ZHOU Yali, ZHOU Liang, MAO Pini. Palaeoflood Hydrological Study in the Quyuanhekou Reach in the Upper Reaches of the Hanjiang River.[J]. Resources and Environment in the Yangtze Basin, 2013, 22(12): 1608-1613.

21. Piani C, Weedon G P, Best M, et al. Statistical bias correction of global simulated daily precipitation and temperature for the application of hydrological models [J]. Journal of Hydrology, 2010, 395(3): 199215.

22. Hagemann S, Chen C, Haerter J O, et al. Impact of a statistical bias correction on the projected hydrological changes obtained from three GCMs and two hydrology models [J]. Journal of Hydrometeorology, 2011, 12(4): 556-578.

23. Warszawski L, Frieler K, Huber V, et al. The InterSectoral Impact Model Intercomparison Project (ISIMIP): Project framework [J]. Proceedings of the National Academy of Sciences, 2014, 111(9): 32283232.

24. Schreiber P. Über die Beziehungen zwischen dem Niederschlag und der Wasserführung der Flüsse in Mitteleuropa[J]. Z. Meteorol, 1904, 21(10): 441-452.

25. Ol'Dekop E M. On evaporation from the surface of river basins $[\mathrm{J}]$. Transactions on meteorological observations, 1911, 4: 200.

26. Turc L. Le bilan d'eau des sols: relations entre les précipitations, l'évaporation et l'écoulement[D]. Institute National de la Recherche Agronomique.1953.

27. Pike J G. The estimation of annual run-off from meteorological data in a tropical climate[J]. Journal of Hydrology, 1964,2(2): 116-123. 
28. Budyko M I. Climate and life. Academic, New York,1974.

29. Fuh Baw-puh. On the Calculation of the Evaporation from Land Surface[J]. Scientia Atmospherica Sinica, 1981,5(1): 23-31.

30. Zhang L, Hickel K, Dawes W R, et al. A rational function approach for estimating mean annual evapotranspiration[J]. Water Resources Research, 2004, 40: W02502.

31. Porporato A, Daly E, Rodriguez-Iturbe I. Soil water balance and ecosystem response to climate change[J]. The American Naturalist, 2004, 164(5): 625-632.

32. Sun Fubao. Study on Watershed Evapotranspiration based on the Budyko Hypothesis [D]. Beijing: Tsinghua University, 2007.

33. Yuan Z, Yan D, Yang Z, et al. Projection of surface water resources in the context of climate change in typical regions of China[J]. Hydrological Sciences Journal, 2017, 62(2): 283-293.

34. Kumar S, Merwade V. Impact of watershed subdivision and soil data resolution on SWAT model calibration and parameter uncertainty[J]. JAWRA Journal of the American Water Resources Association, 2009, 45(5): 1179-1196.

35. PANG Jingpeng, LIU Changming, XU Zongxue. Impact of Land Use Change on Runoff and Sediment Yield in the Miyun Reservoir Catchment[J]. Journal of Beijing Normal University (Natural Science), 2010, 46(3): 290-298.

36. ZHANG Liping, Zeng Sidong, WANG Renchao, XIA Jun. Impacts of Climate Change on the Hydrological Cycle in the Luan River Basin[J].Resources Science, 2011,33 (5) : 966-974.

37. WANG Guoqing, ZHANG Jianyun, LIU Jiufu, JIN Junliang, Liu Cuishan. The Sensitivity of runoff to Climate Change in Different Climatic regions in China[J]. Advances in Water Science, 2011, 22(3): 307-314.

38. Chiew, F.H.S. Estimation of rainfall elasticity of streamflow in Australia [J]. Hydrological Sciences Journal, 2006, 51,613-625. 